\title{
Foot Problems in a Group of Patients with Rheumatoid Arthritis: An Unmet Need for Foot Care
}

\author{
Pinar Borman*, Figen Ayhan, Figen Tuncay and Mehtap Sahin
}

Ankara Training and Research Hospital, Clinic of Physical Medicine and Rehabilitation, Cebeci, Ankara, Turkey

\begin{abstract}
Objectives: The aim of this study was to evaluate the foot involvement in a group of RA patients in regard to symptoms, type and frequency of deformities, location, radiological changes, and foot care.

Patients and Methods: A randomized selected 100 rheumatoid arthritis (RA) patients were recruited to the study. Data about foot symptoms, duration and location of foot pain, pain intensity, access to services related to foot, treatment, orthoses and assistive devices, and usefulness of therapies were determined by the questionnaire. Radiological changes were assessed according to modified Larsen scoring system. The scores of disease activity scale of 28 joints and Health Assessment Questionnaire indicating the functional status of RA patients were collected from patient files.

Results: A total of $100 \mathrm{RA}$ patients ( 90 female, 10 male) with a mean age of $52.5 \pm 10.9$ years were enrolled to the study. Eighty-nine of the 100 patients had experienced foot complaints/symptoms in the past or currently. Foot pain and foot symptoms were reported as the first site of involvement in 14 patients. Thirty-six patients had ankle pain and the most common sites of the foot symptoms were ankle (36\%) and forefoot (30\%) followed by hindfoot (17\%) and midfoot (7\%) currently.

Forty-nine of the patients described that they had difficulty in performing their foot care. Insoles and orthopedic shoes were prescribed in 39 patients, but only 14 of them continued to use them. The main reasons for not wearing them were; 17 not helpful $(43 \%), 5$ made foot pain worse $(12.8 \%)$, and 3 did not fit $(7.6 \%)$. Foot symptoms were reported to be decreased in $24 \%$ of the subjects after the medical treatment and 6 patients indicated that they had underwent foot surgery.

Current foot pain was significantly associated with higher body mass index and longer disease duration, and duration of morning stiffness. The radiological scores did not correlate with duration of foot symptoms and current foot pain ( $p>0.05$ ) but the total number of foot deformities was found to be correlated with Larsen scores $(p<0.05)$.

Conclusion: In our study, foot involvement and foot symptoms were seen frequently in RA but there is an unmet need for provision and monitoring of foot care in patients suffering from this chronic disease.
\end{abstract}

Keywords: Rheumatoid arthritis, foot, foot care.

\section{INTRODUCTION}

Rheumatoid Arthritis (RA) is a chronic inflammatory disorder affecting primarily cartilage and bone of small and middle-sized joints $[1,2]$. The synovial inflammation and destruction of joints lead to pain, loss of function, muscle atrophy that results with disability and reduced quality of life $[2,3]$. The frequency of foot involvement and rheumatoid foot problems have previously been reported from different point of views [4-15].

Various types of foot deformities can result according to the pattern of joint involvement in RA. Within the foot, the subtalar and mid-tarsal joints are more frequently involved than the ankle joint. The ankle is usually quite stable, but reduced dorsal flexion may interfere with walking ability. The subtalar and talonavicular joints are commonly affected in RA. Synovitis causes pain and stiffness and sometimes

*Address correspondence to this author at the Zirvekent Mimoza Sitesi A-1 Blok No: 59, Cankaya, Ankara, Turkey; Tel: 90.312 .595 3391;

Fax: 90.312.363 3396; E-mail: pinarborman@gmail.com leads to subtalar dislocation. As cartilage loss and bone erosion develop, valgus deformity increases with progressive flattening of the longitudinal arch. Forefoot deformity starts with synovitis of the MTP-joints and the involvement of the flexor tendons. The synovitis and erosion occur in metatarsal heads resulting in joint contractures and dislocation, and can lead to extreme pain. Weight bearing in the active stage of RA, may be followed by hallux valgus, hallux rigidus, mallet toe, claw toe and splay toe deformities. In the midfoot, pes planus is the most commonly seen deformity. Calcaneal varus and valgus deformities can also develop in the hind foot [16-18].

Although patients with RA complain of foot pain and disability due to foot problems, physicians generally overlook or neglect the feet in routine clinical examination. Outcome measures such as the DAS 28 , is generally used to assess disease activity and helps to define clinical remission of the disease. Unfortunately, feet and ankles are not included as part of the DAS 28 scoring system and accordingly the feet joints are ignored in routine rheumatologic evaluation and even patients in remission may 
suffer from foot disease activity, as shown in previous studies $[19,20]$.

The aim of this study was to evaluate the foot involvement in regard to symptoms, type and frequency of deformities, location, radiological changes, and foot care in a group of RA patients.

\section{PATIENTS AND METHODS}

A hundred and twenty-four patients with RA, who met the ACR revised criteria [21] for RA, were enrolled from the outpatient clinics of Ankara Training and Research Hospital, Rheumatology unit of Physical Medicine and Rehabilitation Clinic, between 2010 January and 2010 June. The local ethics committee of Ankara Training and Research Hospital approved the study.

Patients aged $<18$, and $>80$ years, having a history of trauma to foot, having comorbid diseases that may relate to foot pain (neuropathy, lumbar radiculopathy, diabetes mellitus, inflammatory rheumatic disease other than RA, and endocrine arthropathies) were not included to the study. 124 patients with rheumatoid arthritis were assessed for eligibility. 4 patients refused to participate in the study and 20 patients were excluded due to age or comorbid diseases. Therefore 100 RA patients were included to the study. Informed consent was obtained from all of the patients.

Demographic characteristics including age, sex, body mass index of all subjects, duration of disease, duration of foot symptoms and drug intake of RA patients were recorded. All patients underwent a clinical interview and physical examination to determine foot related problems and fulfilled a questionnaire assessing the foot problems [6]. Data about foot symptoms, duration and location of foot pain, pain intensity, access to services related to foot (orthopaedics, physiatry, primary care physician), treatment (medical / surgical), interventions for alleviating foot symptoms (orthoses and assistive devices), and usefulness of therapies were determined by this questionnaire. The location of pain in the feet was classified according to ankle, forefoot, mid foot and hind foot. A picture of feet indicating different anatomical sites in the foot was shown and patients were asked to point out the painful areas [6]. In addition a researcher examined the foot by palpation and recorded the tender and painful sites according to the different anatomical regions; including forefoot (the most anterior section of the foot comprising the metatarsal and phalangeal bones, the long bones anterior to the arch of the foot and the bones of the toes), mid foot (the section of the foot in the front of the anklereferring to as the arch and including five articulating bones of the tarsus: the cuboid, navicular and three cuneiform bones), hind foot (the posterior portion of the foot, comprising the region of talus and calcaneus), and the ankle (the region where the foot and the leg meet; talocrural joint). Radiological changes in the foot $\mathrm{x}$-rays of the patients were assessed according to modified Larsen scoring system [22].

The disease activity scores (DAS 28) [23] and scores of Health Assessment Questionnaire (HAQ) [24] indicating the functional status of RA patients and the positivity of rheumatoid factor and anti-CCP were collected from patient files.

\section{Statistical Analysis}

Descriptive statistics were performed and indicated as mean \pm standard deviation and median (minimummaximum) for continuous variables. All qualitative data are expressed as frequencies and percentages. The two independent group comparisons were performed by student $t$ test and Mann Whitney U test. Spearman's rho and Pearson correlation test were used to evaluate correlation between continuous variables and Fisher's exact outcome chi square test were used to examine the differences between groups in terms of categorical variables. $\mathrm{P}$ values less than 0.05 were considered significant. All statistical analyses were done using SPSS for windows version 15.0 program.

\section{RESULTS}

Demographic and clinical characteristics of the study population are presented in Table 1. Seventy-nine (79\%) patients were using methotrexate-MTX- (10-20 mg/week) and other disease modifying anti-rheumatic drugs (DMARDs). Of those $22(27.8 \%)$ patients were on sulphasalasine-SSZ-, $34(43 \%)$ patients were on hydroxychloroquine-HCQ-, and 24 patients (30.3\%) were on corticosteroid therapy (less than $15 \mathrm{mg} /$ day) in addition to MTX. Twelve (12\%) patients were on leflunomide and $9(9 \%)$ patients were on both HCQ and SSZ. Thirty-nine (39\%) patients were using non-steroid anti-inflammatory drugs (NSAIDs). Sixty-one patients were using oral MTX, while 18 patients were on subcutaneous MTX therapy.

Table 1. Demographic and Clinical Characteristics of the Study Population

\begin{tabular}{|l|c|}
\hline & $\begin{array}{c}\text { Mean } \pm \text { SD or Median } \\
\text { (Minimum-Maximum), } \mathbf{n}=\mathbf{1 0 0}\end{array}$ \\
\hline \hline Mean age (years) & $52.5 \pm 10.9(27-79$ years) \\
\hline Sex (F/M) & $90 / 10$ \\
\hline Body mass index (kg/m $\mathbf{m}^{\mathbf{2}}$ & $29.4 \pm 5.6(17.1-52.3)$ \\
\hline Duration of disease (years) & $12(1-30)$ \\
\hline Duration of foot pain (years) & $12(1-35)$ \\
\hline Foot pain-VAS (mm) & $47(0-100)$ \\
\hline DAS28 score & $4.2(2.7-5.4)$ \\
\hline HAQ score & $0.25(0-1.75)$ \\
\hline Larsen score & $6.0(0-64)$ \\
\hline ESR (mm/hr) & $38.0(13.0-57.0)$ \\
\hline CRP $(\mathbf{g} / \mathbf{d L})$ & $0.7(0.3-1.9)$ \\
\hline RF-positivity \% & 64 \\
\hline CCP-positivity \% & 53 \\
\hline
\end{tabular}

Eighty-nine of the 100 patients (89\%) had experienced foot complaints / symptoms in the past or currently. Foot pain and foot symptoms were reported as the first site of involvement in 14 patients. Sixty-five patients had ankle pain in the past and the most common sites of the foot symptoms in the past were ankle $(\% 36)$, forefoot $(35 \%)$ followed by hindfoot (34\%) and midfoot (12\%). The distribution of current foot pain, physical findings according to sites and foot symptoms are shown in Table $\mathbf{2}$. Ankle joint was the most common painful site (\%36) in our sample. 
Table 2. The Frequency and Distribution of Current Foot Pain; that was Based on Examination, and Foot Complaints in Patients with Rheumatoid Arthritis

\begin{tabular}{|l|c|}
\hline \multicolumn{2}{|c|}{ Current Symptom } \\
\hline \hline Foin location & \# of Pateints \\
\hline Mid foot pain & 30 \\
\hline Hind foot pain & 7 \\
\hline Ankle pain & 17 \\
\hline Non-pain foot complaints & 36 \\
\hline Swelling in the foot & 51 \\
\hline Numbness in the foot & 68 \\
\hline Corns & 51 \\
\hline Ulcer & 24 \\
\hline Bunion & 1 \\
\hline Flat foot & 14 \\
\hline Toe nail problems & 11 \\
\hline Others & 37 \\
\hline
\end{tabular}

The first examining physician for the foot problems was the physiatrist in 54 patients, orthopedic surgeon in 14 patients, and primary care physician for the remaining.
Forty-nine of the patients described that they had difficulty in performing their foot care. Insoles and orthopedic shoes were prescribed in 39 patients, but only 14 of them continued to use them. They mostly didn't satisfy with the silicon insoles that were prescribed to support the medial longitudinal and transverse arches. The main reasons for not wearing them were described as 'not helpful' in 17 patients $(43 \%)$, 'made foot pain worse' in 5 patients $(12.8 \%)$, and 'did not fit' in 3 patients $(7.6 \%)$. Foot symptoms were reported to be decreased in $24 \%$ of the subjects after the medical treatment and 6 patients indicated that they had underwent foot surgery.

According to genders; high rates of foot pain during the past month were reported by both genders with a trend for women to report foot pain more intensively than men but the difference was not statistically significant. The most common foot symptoms and intensity of foot pain according to genders are shown in Table $\mathbf{3}$.

No correlation was observed between current foot pain and demographic parameters like age and gender but current foot pain was significantly associated with higher BMI and longer disease duration $(r=0.24, p=0.01, r=0.23, p=0.01)$. Corticosteroid therapy was correlated with current foot pain $(\mathrm{r}=0.24, \mathrm{p}=0.01)$.

The radiological scores did not correlate with duration of foot symptoms and current foot pain $(p>0.05)$ but the total number of foot deformities was found to be correlated with Larsen scores $(\mathrm{r}=0.26, \mathrm{p}=0.001)$. No correlation was observed between HAQ scores and deformities.

Table 3. Pain Intensity, Location of Foot Pain and Foot Symptoms in the Patients According to the Sex

\begin{tabular}{|c|c|c|c|}
\hline Foot pain-VAS & $24.6 \pm 25.5($ median 20$)$ & $13.0 \pm 19.0($ median 0$)$ & $0.183^{*}$ \\
\hline Duration of symptoms (years) & $10.5 \pm 9.0$ & $7.4 \pm 7.7$ & $0.243 * *$ \\
\hline \multicolumn{4}{|l|}{ Current pain } \\
\hline Current pain in hindfoot & $15(16.7 \%)$ & $2(20 \%)$ & $0.79 * * *$ \\
\hline Current pain in ankle & $34(37.8 \%)$ & $2(20 \%)$ & $0.29 * * *$ \\
\hline \multicolumn{4}{|l|}{ Past pain } \\
\hline Forefoot pain in the past & $49(54.4 \%)$ & $5(50 \%)$ & $0.71 * * *$ \\
\hline Ankle pain in the past & $60(66.7 \%)$ & $5(50 \%)$ & $0.29 * * *$ \\
\hline Corns & $21(23.3 \%)$ & $3(30 \%)$ & $0.83 * * *$ \\
\hline Ulcer & $1(1.1 \%)$ & 0 & $0.65 * * *$ \\
\hline Bunion & $13(14.4 \%)$ & $1(10 \%)$ & $0.45^{* * *}$ \\
\hline Flat foot & $11(12.2 \%)$ & 0 & $0.54 * * *$ \\
\hline Others & $5(5.6 \%)$ & 0 & $0.32 * * *$ \\
\hline
\end{tabular}

*Mann-whitney U test.

$* *$ Student-t test.

*** Fisher's exact outcome chi square test 


\section{DISCUSSION}

The studies evaluating foot involvement in RA reported the foot involvement in 56-100\% of the patients [4-11, 13$15]$. We found a $89 \%$ of foot involvement in RA patients, consistent with the previous data. We indicated the most frequent involvement in the ankle and fore foot, followed by hind foot and mid foot currently, in accordance with previous data $[6,8,11,12,24-27]$. According to genders the frequency of foot involvement was reported in $91 \%$ females and $81 \%$ males in some previous studies [6]. In our RA patients the ratios were $94 \%$ and $50 \%$ for females and males respectively. The most common involvement was ankle in females and ankle and hind foot in males. But our study group was small and not enough to conclude gender differences.

High body mass index or disease duration were found to be correlated with foot problems possibly because of excessive mechanical load and joint damage process, respectively. The duration of the disease and duration of foot pain were nearly the same which may be due to early involvement of foot joints in our sample.

The epidemiology of foot involvement has previously studied in a number of studies, most of them investigated low number of subjects and/or localized foot disease and focusing only on clinical or radiological changes, rather than views and perceptions of the patients with RA $[5,7,8,13$, 18]. The exceptions were the studies of Otter et al., and Rome et al. [6, 15]. Otter et al. included a large cohort of people with RA in UK was evaluated for foot involvement and access to foot care, in a perspective from the patients [6]. Rome et al. indicated only $24 \%$ of patients that have used podiatry service and highlighted the problems of footwear [15]. Also Naidoo et al. explored the perceptions of women with RA regarding their choice of retail footwear and the factors influencing foot wear selection [28]. We have evaluated the foot involvement as clinical, radiological and from the view of subjects in a group of patients suffering from RA. Our study indicates the main types of foot involvement in RA patients associated with their point of view. Our study confirms a high rate of foot problems and comparable data to other reports previously published [10]. Fifty-one percent of the patients in our study reported current non-painful foot problems. This corresponds well with the results of earlier studies, with frequencies of current foot involvement between $77-94 \%[2,5,6,8,29-31]$. The rate of foot involvement was higher in our study and current foot pain was relatively less common in our cohort, which could be described by the intensive drug use and moderate disease activity status. RA patients reported a range of foot symptoms which varied in both intensity and severity. Among the specific foot deformities studied, hallux valgus/bunion and corns were the most prevalent ones. However, it was difficult to say that these problems were related to RA because of common complaints in the general population. Other findings including swelling in the foot $(68 \%)$, numbness in the foot $(51 \%)$, toe nail problems $(37 \%)$, and ankle pain (36\%) may be attributed to RA since their high percentages compared to the low prevalence diagnosis of general population.

In our study we have additionally evaluated RA patients' perceptions of foot symptoms. Totally $89 \%$ of patients needed professional help for their foot pain and approximately half of the patients described difficulty in performing their foot care. We indicated that most of the patients with foot pain had shared their foot symptoms with their physician, partly with the physiatrist. Foot insoles and orthoses were prescribed by physicians to improve foot function but the adherence to nonsurgical interventions was only $36 \%$ in our study. The prescription of insoles was stated as $5-15 \%[2,6,31]$ of RA patients in previous studies, with an exception Grondal et al. who determined this prescription in two thirds of their patients [8]. The prescription of the insoles and orthopedic shoes were $39 \%$ in our study group, comparable to the results of Otter et al. [6] with a prescription rate of $44.2 \%$. But only $14 \%$ of our subjects continued to wear these orthoses. Reasons for the limited uptake of special footwear were complex and multifactorial, similar to the previous data $[6,17,19]$. The most common reason for non-adherence was reported as these devices did not improve their symptoms or did not fit well in our RA group. But this was not surprising as previous studies indicated the limited and conflicted evidence of the foot orthoses in improvement of foot pain and functional disability among patients with RA [32,33]. The orthoses were reported to decrease forefoot pain and rearfoot pain in patients with early-onset RA but were not shown to improve pain levels in advanced disease [28, 33]. Also the costeffectiveness of foot orthoses in RA patients was suggested to be furtherly clarified $[6,28]$. Many people with RA do not wear the prescribed therapeutic footwear, often due to poor fit or unacceptable cosmetic appearances. The appearance and design of the footwear was of considerable consequence for non compliance. Difficulties with the fit of the orthoses to their retail shoes were also emphasized in some previous studies $[6,28,32]$. The non-adherence of the prescription of foot orthoses may also be related to the lack of regular follow-ups and/or poor education of the patients and physicians.

Orthopedic RA-related surgery of the foot has a strong effect on pain and physical function in patients that do not respond to conservative clinical approaches. In intermediate to severe stages of the disease, conventional surgical treatment involves both joint preserving and joint sacrificing surgery to relieve pain and correct deformity in the rheumatoid forefoot [34]. Some previous authors suggest as earlier as but less radical foot surgery $[35,36]$. But in recent years, surgical procedures have been decreased in RA patients as shown by Weiss et al. [37]. Surgery had been reported in 5-22\% of the RA patients with forefoot and hindfoot/ankle problems $[5,6,8,35-37]$. Surgery had been performed in $6 \%$ of our cases, which is similar to some previous data $[5,6,8]$. As the number of patients with foot surgery was small, we could not classify surgeries according to sites and could not compare our patients with the subjects of previous studies [5, 6, 8, 35-37].

Although the foot symptoms and secondary limitations on activities of daily living are common problems in RA patients, the examination of foot is generally neglected in routine clinical practice $[6,8,9]$. Foot examination is an important factor for predicting disability, which is also the main predictor of poor outcome in RA patients. We have indicated that functional status scores are not correlated with current foot pain in our RA patients, similar to some 
previous data $[10,11]$. In our study we have performed HAQ to assess functional status which consists of questions mostly about the upper extremity function and DAS28 to assess disease activity which neglect foot joints. Previous studies using specific foot questionnaires indicated a close relationship between foot symptoms and functional disability [11]. In this study we did not use a specific foot function index which could be a major limitation of the study.

Our study is the first study evaluating foot impairment clinically and from patients' perspective in a group of Turkish patients with RA, and foot abnormalities are found to be various and common in this population. We have also determined a probable lack of compliance with recommendations and/or education of patients and physicians, as most of the RA patients did not use their orthothic devices.

In conclusion, foot involvement and foot symptoms are seen frequently in RA. Physicians should be encouraged performing the physical examination of the feet, assessment and treatment of foot problems during the follow-ups. Individual proper medication and orthoses should be prescribed by the physicians and the management and compliance to insoles should be monitored as a part of treatment in order to enhance the quality of life of the patients suffering from this chronic condition.

\section{ACKNOWLEDGEMENT}

Declared none.

\section{CONFLICT OF INTEREST}

The authors confirm that this article content has no conflict of interest.

\section{REFERENCES}

[1] Brasington RD. Clinical features of rheumatoid arthritis. In: Hochberg MC, Silman AJ, Smolen JS, Eds. Rheumatology. 5th ed. Philadelphia: Mosby-Elsevier 2011. pp. 829-38.

[2] Michelson J, Easley M, Wigley FM, Hellmann D. Foot and ankle problems in rheumatoid arthritis. Foot Ankle Int 1994; 15: 608-13.

[3] Borman P, Toy GG, Babaoğlu S, Bodur H, Ciliz D, Alli N. A comparative evaluation of quality of life and life satisfaction in patients with psoriatic and rheumatoid arthritis. Clin Rheumatol 2007; 26: 330-4

[4] Spiegel TM, Spiegel JS. Rheumatoid arthritis in the ffot and anklediagnosis, pathology and treatment: the relationship between foot and ankle deformity and disease duration in 50 patients. Foot Ankle 1982; 26: 318-24.

[5] Matricali GA, Bonen A, Verduyckt J, et al. The presence of forefoot problems and the role of surgery in patients with rheumatoid arthritis. Ann Rheum Dis 2006; 65: 1254-5.

[6] Otter SJ, Lucas K, Springett K, et al. Foot pain in rheumatoid arthritis prevalence, risk factors and management: an epidemiological study. Clin Rheumatol 2010; 29: 255-71.

[7] Shi K, Tomita T, Hayashida K, et al. Foot deformities in rheumatoid arthritis and relevance of disease severity. Foot $\mathrm{J}$ Rheumatol 2000; 27: 8-9.

[8] Grondal L, Tengstrand B, Nordmark B, et al. The foot: stil the most important reason for walking incapacity in rheumatoid arthritis: distribution of symptomatic joints in 1000 rheumatoid arthritis patients. Acta Orthop 2008; 79: 257-261.

[9] Baan H, Drossaers-Bakker W, Dubbeldam R, Van de Laar M. We should not forget the foot relations between signs and symptoms, damage and function in rheumatoid arthritis. Clin Rheumatol 2011; 30(11): 1475-9.

[10] Rojas-Villaraga A, Bayona J, Zuluoga N, et al. The impact of rheumatoid foot on disability in Colombian patients with rheumatoid arthritis. BMC Musculoskelet Disord 2009; 10: 67-73.
[11] Bal A, Aydog E, Aydog ST, Cakci A. Foot deformities in rheumatoid arthritis and reklvance of foot function index. Clin Rheumatol 2006; 25: 671-5.

[12] Van der Leeden M, Steultjiens MPM, van Schaardenburg D, Dekker J. Forefoot disease activity in rheumatoid arthritis patients in remission: results of a cohort study. Arthritis Res Ther 2010; 12: R3

[13] Lahkamp M, Burrow G, McCarron T, et al. The prevalence and anatomical location of foot pain in early diagnosed patients with rheumatoid arthritis. Br J Podiatry 2006; 9: 115-9.

[14] O'Connell PG, Siegel KL, Keple TM, et al. Forefoot deformity, pain and mobility and rheumatoid and nonarthritic subjects. J Rheumatol 1998; 25: 1081-6.

[15] Rome K, Gow PJ, Dalbeth N, Chapman JM. Clinical audit of foot problems in patients with rheumatoid arthritis treated at Counties Manukau District Health Board, Auckland, New Zealand. J Foot Ankle Res 2009; 2: 16

[16] Linholm RV. The rheumatoid foot. Clin Orthop Relat Res 1992; 265: 4-8.

[17] Melvin HJ. Disorders of the foot and ankle. In: Nasim AR, editor Rheumatoid arthritis, other collagen diseases and psoriasis of the foot. Philadelphia: Saunders 1992; pp.1719-51.

[18] Abdo RV, Lorio LJ. Rheumatoid arthritis of the foot and ankle. J Am Acad Orthop Surg 1996; 12: 326-32.

[19] Van der Leeden M, Stevitjiens MP, Ursum J, et al. Prevalence and course of forefoot impairments and walking disability in the first eight years of rheumatoid arthritis. Arthritis Rheum 2008; 59: 1596-602.

[20] Landewe R, van der Heijde D, Linden S, van der Boers M. Twentyeight joint counts invalidate the DAS 28 remission definition owing to the omission of the lower extremity joints: a comparison with the original DAS remission. Ann Rheum Dis 2006; 65: 637-41.

[21] Arnett FC, Edworthy SM, Block DA, et al. American College of Rheumatology 1987 revised criteria fort he classificaiton of rheumatoid arthritis. Arthritis Rheum 1988; 31: 315-24.

[22] Rau R, Herborn G. A modified version of Larsen's scoring method to assess radiological changes in rheumatoid arthritis. J Rheumatol 1995; 10: 1976-82.

[23] Villaverde V, Balsa A, Cantelejo M, et al. Activity indices in rheumatoid arthritis. J Rheumatol 2000; 27: 2576-84.

[24] Kucukdeveci AA, Sahin H, Ataman S, Griffiths B, Tennant A. Issues in cross-cultural validity testing of a Turkish version of the Stanford health assessment questionnaire. Arthritis Rheum 2004; 51: 14-9.

[25] Kuper HH, van Leeuwen MA, van Riel PL, et al. Radiographic damage in large joints in early rheumatoid arthritis: relationship with radiographic damage in hands and feet, disease activity and physical disability. Br J Rheumatol 1997; 36: 856-60.

[26] Molenaar ET, Vaskuyl AE, Dijkmans BA. Functional disability in relation to radiological damage and disease activity in patients with rheumatoid arthritis in remission. J Rheumatol 2002; 29: 267-70.

[27] Johnson KA. Rheumatoid arthritis-forefoot, surgery of the foot and ankle. New York: Raven 1994; pp. 245-64.

[28] Naidoo S, Anderson S, Mills J, et al. 'I could cry, the amount of shoes Ican't get into'. A qualitative exploration of the factors that influence retail footwear selection in women with rheumatoid arthritis. J Foot Ankle Res 2011; 4: 21.

[29] Vainio K. The rheumatoid foot: a clinical study with pathological and roentgenological comments. Ann Chir Gynaecol 1956; 45 (Suppl 1): 19-34

[30] VidigalE, Jacoby RK, Dixon AS, et al. The foot in chronic rheumatoid arthritis. Ann Rheum Dis 1975; 34: 292-7.

[31] Kerry RH, Holt G, Stockley I. The foot in chronic rheumatoid arthritis: a continuing problem. The Foot 1994; 4: 201-3.

[32] Clark H, Rome K, Plant M, et al. A critical review of foot orthoses in the rheumatoid arthritic foot. Rheumatology 2006; 45: 139-45.

[33] Silvester RN, Williams AE, Dalbeth N, Rome K. 'Choosing shoes': a preliminary study into the challenges facing clinicians in assessing footwear for rheumatoid patients. J Foot Ankle Res 2010; 3: 24 .

[34] Bhavikatti M, Sewell MD, Al-Hadity N, Awan S, Bawarish MA. Joint preserving surgery for rheumatoid forefoot deformities improves pain and corrects deformity at midterm follow-up. Foot (Edinb) 2012; 22(2): 81-4

[35] Backhouse MR, Keenan AM, Hensor EMA, et al. Use of conservative and surgical foot care in an inception cohort of 
patients with rheumatoid arthritis. Rheumatology 2011; 50: 158695.

[36] Boonen A, Matricali GA, Verduyckt J, et al. Orthopedic surgery in patients with RA: a shift towards more frequent and earlier nonjoint sacrificing surgery. Ann Rheum Dis 2006; 65: 694-5
[37] Weiss RJ, Stark A, Wick MC, et al. Orthopedic surgery of the lower limbs in 49.802 rheumatoid arthritis patients: Results from the Swedish National Inpatient Registry during 1987-2001. Annals Rheum Dis 2006; 65: 335-41.

(C) Borman et al.; Licensee Bentham Open.

This is an open access article licensed under the terms of the Creative Commons Attribution Non-Commercial License (http://creativecommons.org/licenses/by-nc/ $3.0 /$ ) which permits unrestricted, non-commercial use, distribution and reproduction in any medium, provided the work is properly cited. 